\title{
Syringomyelia associated with post-meningitic spinal arachnoiditis due to Candida tropicalis
}

\author{
Kammant Phanthumchinda and Surachai Kaoropthum
}

Departments of Medicine and Surgery, Faculty of Medicine, Chulalongkorn University, Bangkok 10330, Thailand

\begin{abstract}
Summary: A 63 year old man who suffered from syringomyelia related to post-meningitic spinal arachnoiditis caused by Candida tropicalis is reported. The clinical syndrome of syringomyelia developed gradually and a definite diagnosis was delayed for more than 10 years. The patient has partially recovered after surgical treatment. This form of fungal infection and its delayed neurological complication in the form of syringomyelia has not been reported previously, to our knowledge.
\end{abstract}

\section{Introduction}

Cavitation of the spinal cord can be associated with several underlying conditions. ${ }^{1}$ Syringomyelia has been used to denote dilatation associated with acute infarction of the cord, scarring from chronic arachnoiditis, intramedullary tumour, or trauma. ${ }^{2}$ Hydromyelia has been used to denote persistent dilatation of the central canal associated with congenital defects. However, the term syringomyelia is used preferentially for both conditions. ${ }^{2}$

The most common cause of syringomyelia is congenital. Syringomyelia associated with infectious arachnoiditis is rare. ${ }^{3}$ To the best of our knowledge, syringomyelia associated with postmeningitic arachnoiditis caused by Candida tropicalis has not been previously reported.

\section{Case report}

A 63 year old man had a subacute onset of fever, headache, nausea and vomiting for 2 weeks in 1973. He was admitted to a university hospital where examination disclosed fever, a stiff neck and bilateral papilloedema. The cerebrospinal fluid disclosed an inflammatory profile and culture revealed Candida tropicalis. He was successfully treated with amphotericin B and 5-fluorocytosine. He was hospitalized for 4 months. After discharge he had no meningeal symptoms or signs. However,

Correspondence: K. Phanthumchinda, M.D., Department of Medicine, Faculty of Medicine, Chulalongkorn University, Bangkok 10330, Thailand.

Accepted: 12 March 1991 he developed mild weakness of the left leg which resolved within 6 months.

In 1975, he noticed numbness of both feet. Physical examination revealed relative hypoalgesia of both feet, positive bilateral Babinski's signs, intact joint position sense and normal deep tendon reflexes.

During 1976-1980, he had pain of the left chest wall, constipation and the numbness of his feet was worse. Follow-up examination at the same hospital did not disclose any significant changes.

During 1985-1990, in addition to his unresolved symptoms, he had progressive weakness and atrophy of his left leg muscles, sexual impotence and incontinence of urine. His functional ability had progressively worsened. Myelography was unremarkable and physiotherapy was recommended. His symptoms progressed and he was admitted to our unit.

Physical examination revealed a Trendelenberg gait with hyperlordosis. There was atrophy and weakness of grade IV/V (MRC) of the left buttock, thigh and leg. Generalized hyperreflexia was noted with hypertonicity of lower extremities and bilateral Babinski's signs. Anal sphincter tone was poor with absence of the anal reflex. There was loss of pain sensation at the level of $T_{5}-T_{8}$ but posterior column and tactile sensation were spared. Routine blood tests and cerebrospinal fluid examination were normal.

Magnetic resonance imaging (MRI) of the spinal cord showed abnormal low signal intensity in the central part of the spinal cord in $T_{1}$ weighted images from the level of $\mathrm{C}_{5}-\mathrm{T}_{11}$ (Figure 1). In $\mathrm{T}_{2}$ weighted images, this area was of high signal 


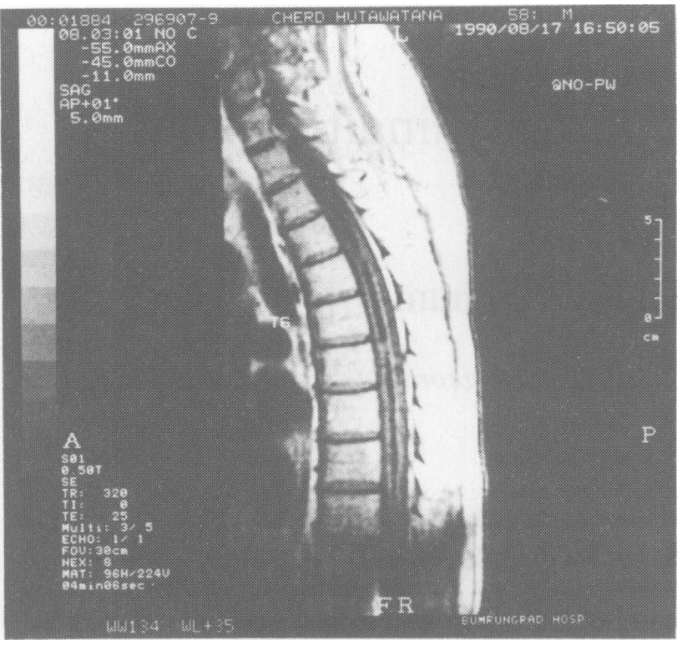

Figure 1 MRI revealed longitudinal section of the spinal cord showing syringomyelic cavity extending from $C_{5}-T_{1}$.

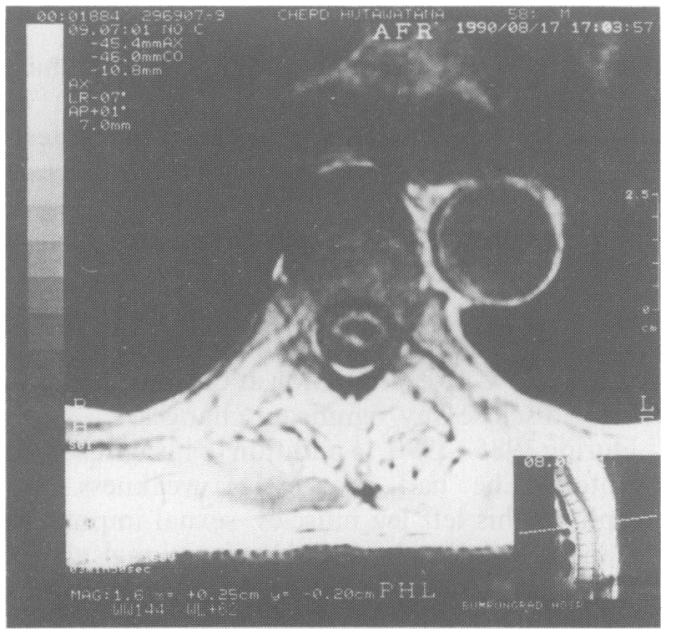

Figure 2 MRI revealed cross section of the spinal cord showing irregular syringomyelic cavity and thickening and irregular arachnoid surrounding the cord.

intensity. The cavity was largest between $T_{6}-T_{7}$, about $0.4-1 \mathrm{~cm}$, and the cord was paper thin. In the thoracic area, the cavity was irregular in size. The cord outline was irregular with nonhomogeneous signal intensity of the subarachnoid space around the cord at the $T_{4}-T_{5}$ level (Figure 2). Neither a Chiari malformation nor a communication between the dilated central canal and the fourth ventricle was demonstrated.

Total laminectomy of $T_{6}$ and $T_{7}$ was performed and the dura was opened. There was marked arachnoid thickening and adhesions. The spinal cord was enlarged. The thickened arachnoid was removed from the spinal cord. The dorsal root entry zone on the left side was very thin. A small opening was made on the spinal cord at the root entry. A silicone tube was inserted into the cavity which filled with clear colourless cerebrospinal fluid. The tube was connected to the pleural cavity. Microscopic section of thickened arachnoid confirmed severe fibrosis of the meninges.

After a 6-month follow-up period, examination revealed that atrophy, weakness and gait were improved but that the sensory and autonomic function persisted.

\section{Discussion}

Spinal arachnoiditis or scarring of the spinal meninges can be due to noninfectious or infectious inflammatory processes of the spinal leptomeninges. The non-infectious group includes chemical agents, subarachnoid haemorrhage, diseases of the spinal column, lumbar disc disease and idiopathic adhesive arachnoiditis. ${ }^{4}$ The post-infectious group includes viral, bacterial and fungal infections..$^{5-13}$ Only two well documented cases of fungal arachnoiditis have been reported due to chromoblastomycosis and cryptococcosis. ${ }^{12,13}$

C. tropicalis, ${ }^{14}$ a fungus not uncommonly found in the mucosa of the gastrointestinal tract ando vagina, may become pathogenic. ${ }^{15,16}$ Human $C$. tropicalis-induced diseases reported are septicaemia, ${ }^{17}$ endocarditis, ${ }^{17}$ vulvovaginitis, ${ }^{18}$ bronchopulmonary disease, ${ }^{19}$ orbital infection ${ }^{20}$ and osteomyelitis. ${ }^{20}$ Our patient suffered from subacute meningitis due to $C$. tropicalis followed by chronic spinal arachnoiditis 17 years later. This form of $C$. tropicalis infection and its delayed complication has not been reported previously.

Symptoms of chronic spinal arachnoiditis are most likely due to constriction, irritation from adhesions or pressure produced by fluid filled cysts or syringomyelic changes in the cord. ${ }^{1,3}$ Our patient had syringomyelic changes and a dramatic improvement in motor function after insertion of a shunt. This indicated that syringomyelic change might have been at least partially responsible for his clinical manifestations. The clinical picture of chronic spinal arachnoiditis depends on the level of lesions and may manifest as a spinal cord or spinal nerve root syndrome or combined syndrome. The onset and clinical course may be acute, subacute or chronic with or without remission. ${ }^{1,3}$ The signs may be scattered, ill-defined or poorly localized in some cases. Our patient had subacute weakness of the left leg, 4 months after his $C$. tropicalis meningitis. This episode ended in a spontaneous remission. However, he developed a chronic progressive syringomyelia 2 years later. His clinical signs and 
symptoms were ill-defined and the diagnosis was delayed for more than 10 years.

Although spinal arachnoiditis is known to be associated with syringomyelia, the mechanism of cavitation is poorly understood. Proposed mechanisms include obliteration of spinal blood supply from arachnoiditis causing myelomalacia and eventually syringomyelia. ${ }^{3}$ However, altera-

\section{References}

1. Barnett, H.J.M., Foster, J.B. \& Hudgson, P. Syringomyelia. W.B. Saunders, London, 1973.

2. Carmel, P.W. The Chiari malformations and syringomyelia. In: Hoffman, H.J., Epstein, F. (eds) Disorders of the Developing Nervous System: Diagnosis and Treatment. Blackwell Scientific Publications, Boston, 1986, pp. 133-151.

3. Caplan, L.R., Norohna, A.B. \& Amico, L.L. Syringomyelia and arachnoiditis. J Neurol Neurosurg Psychiatry 1990, 53: 106-113.

4. Massey, E.W. Disorders of bones, joints ligaments, cartilage and meninges. In: Bradley, W.G., Daroff, R.B., Fenichel, G.M. \& Marsden, C.D. (eds) Neurology in Clinical Practice, vol. 2. Butterworths-Heinemann, Boston, 1990, pp. 1657-1658.

5. Baker, L.F. \& Ford, F.R. Chronic arachnoiditis obliterating the spinal subarachnoid space. JAMA 1937, 109: 785-786.

6. Stookey, B. Adhesive spinal arachnoiditis simulating spinal tumor. Arch Neurol Psychiatry 1927, 17: 151-178.

7. Rocovich, P.M. Adhesive spinal arachnoiditis, Bull Los Angeles Neurol Soc 1947, 12: 69-77.

8. Hekay, R.P. Chronic adhesive spinal arachnoiditis. JAMA 1939, 112: 802-806.

9. Jelsma, F. Cervical intramedullary cyst due to Corynebacterium diphtheriare gravis. Case report. J Neurosurg 1973, 38: $78-80$

10. John, J.F. \& Douglas, G.D. Tuberculous arachnoiditis. $J$ Pediatr 1975, 86: 235-236. tion of cerebrospinal fluid dynamics due to scar formation from arachnoiditis may also contribute to the formation or expansion of the cavity. ${ }^{3}$

Syringomyelia due to arachnoiditis is rare. The possibility that arachnoiditis may be a causative agent in syringomyelia should always be considered.

11. Siddiqui, N.A. Spinal arachnoiditis. Neurology (Bombay) 1968, 16: 131-134.

12. Takahashi, H., Sasaki, A., Arai, T., Tsukamoto, Y., Sato, O. \& Sano, K. Chromoblastomycosis in the cisterna magna and the spinal arachnoid space. J Neurosurg 1973, 38: 506-509.

13. Davison, S. Cryptococcal spinal arachnoiditis. J Neurol Neurosurg Psychiatry 1968, 31: 76-80.

14. Hurley, R. \& Winner, H.J. The pathogenicity of Candida tropicalis. J Path Bact 1962, 84: 33-38.

15. Emmons, C.H.W., Binford, C.H.H. \& Utz, J.P. Medical Mycology. Lea and Febiger, Philadelphia, 1970, pp. 167, 171, 179.

16. Young, R.C., Bennett, J.E., Gulhoed, G.W. \& Levine, H.S. Fungemia with compromized host resistance. Ann Intern Med 1974, 80: 605-612.

17. Tunier, E., Kay, J.H., Bernstein, S., Mendez, M. \& Subiate, P. Surgical treatment of Candida endocarditis. Chest 1975, 67: $262-273$.

18. Gentles, J.C. \& Latouche, C.J. Yeasts as human and animal pathogens. In: Rose, A.M., Harrison, J.S. (eds). The Yeast. Academic Press, London, 1969, pp. 136-138.

19. Bader, G. Candidose. In: Dic viszeralen Mykosen. Fischer, Jena, 1965, pp. 95-156.

20. Segal, E., Romano, A., Eylan, E. \& Stein, R. Isolation of Candida tropicalis from an orbital infection as a complication of maxillary osteomyelitis. Infection 1974, 2: 111-112. 